\title{
Assessment of efficiency and prospects for the use of hybrid thermal low-capacity power plants in the Republic of Vietnam
}

\author{
D. T. Nguen ${ }^{1, *}$, D. N. Pham $^{1}$, G. R. Mingaleeva ${ }^{1}, O . V$. Afanaseva $^{1}$, and $P$. Zunino $^{2}$ \\ ${ }^{1}$ Kazan State Power Engineering University (KSPEU), Kazan, Russia \\ ${ }^{2}$ Università degli Studi di Genova, Genoa, Italy
}

\begin{abstract}
The growing demand for energy and fossil fuels creates increased number of difficulties, while renewable energy sources are still rarely used worldwide, particularly in Vietnam. In this article hybrid thermal power plants based on gas turbine plants are discussed, the increased efficiency of which is achieved by air heating after the compressor in solar air heaters. The basic design equations and the results of evaluating the efficiency and fuel consumption are presented for two thermal power plants of 4.6 MW and 11.8 MW. The dependence of the results on the intensity of solar extraction for the climatic conditions of the Ninh Thuan province of the Republic of Vietnam is discussed.
\end{abstract}

\section{Introduction}

\subsection{The hybrid solar thermal power plant}

According to experts, the main causes of climate change and global warming are greenhouse gas (mainly $\mathrm{CO} 2$ ) emissions. The EIA's International Energy Outlook 2017 Reference predicts that $\mathrm{CO} 2$-related emissions from energy production will grow by $0.6 \%$ annually from 2015 to 2040 [1].

Today, humanity faces the risk of instability in providing energy and reducing energy security, as sources of fossil fuels are gradually being exhausted, while energy consumption is increasing. According to the EIA, the level of energy consumption in the world will increase by $28 \%$ in the period from 2015 to 2040 [2], which will lead to higher prices for fossil fuels in the next 20 years.

The world needs reliable and inexpensive alternative energy sources to reduce pollution and ensure sustainable development. Wind and solar energy are very promising and the unit costs for implementing these projects decrease every year, but wind and solar energy cannot satisfy the energy needs of large consumers. For example, in the United States, according to the data for $2018,30.29 \mathrm{GW}$ of energy was generated on the basis of solar photovoltaic stations, $1.76 \mathrm{GW}$ is for solar thermal energy, and the total energy output was $215.24 \mathrm{GW}$ [3].

Nowadays gas turbine installations are considered to be the most efficient energy-generating equipment, the efficiency of which is more than $40 \%$.

Natural gas, which is a high-calorific and ecological fuel, is used in such installations, and it can become the main fuel during the transition to economy based on renewable energy, in the next several decades.
The hybrid thermal power plants that use both traditional fossil fuels and renewable energy resources can become the basis for such a transition.

Solar thermal power plants use standard power generators, and therefore can easily be combined with other fuel sources $[4,5]$. These sources include gas, coal, biofuel, wind, nuclear energy, etc.

Combining solar energy with other fuels such as natural gas can also benefit conventional thermal power plants, reducing emissions to the atmosphere and fuel costs $[6,7]$.

Such objects can be developed with the prospect of using solar energy, the share of which can be increased, which will contribute to the growth of thermal energy reserves $[8,9]$.

It will allow the power plant to gradually switch to predominant use of solar energy, and to burn natural gas when it has low price and during certain time periods at peak loads. In addition, hybrid solar power plants operating on solid organic or biofuel can reduce the economic and technical barriers associated with pure solar energy [10]. Therefore, it is economically advantageous to create power plants that combine solar energy with fossil fuels $[11,12]$.

\subsection{Concentrated Solar Power}

The concentrated solar power (CSP) is an alternative and renewable energy technology focused on indirect converting of sunlight into electricity. CSP uses a variety of mirrors placed on a large area of earth to direct and concentrate sunlight into a single point known as a receiver. Similar to photovoltaic solar, wind, hydropower and other alternative energy technologies, solar concentrators have the advantage of being sources of renewable, stable or self-sustaining and

* Corresponding author: ductoan.bf@gmail.com 
environmentally friendly energy. CSP technology is particularly promising in regions with high direct sunlight (DNI) solar intensity. According to the expert estimates, CSP can be the source of energy used at peak and intermediate loads in the sunniest areas by 2020 and the main source in the period from 2025 to 2030 [13].

Currently there are four available CSP technologies: Parabolic through collector (PTC), solar power tower (SPT), linear Fresnel reflector (LFR) and parabolic dish system (PDS).

Although the PTC technology is the most mature CSP design, solar tower technology occupies the second place and gains growing importance due to its advantages. The SPT system benefits from high operating temperatures. In addition, SPT technology allows obtaining a higher site gradient than PTC technology does, which reduces the site improvement costs [14]. Designing the SPT system allows the entire pipeline system to be concentrated in the power plant, shortening the piping system and thus reducing energy losses and facilitating the diagnosis of incidents and maintenance [15]. SPT technology has been proven commercially and large SPT facilities are now in operation, for example, Ivanpah Solar Power Facility, which is the largest CSP plant.

\subsection{System overview}

In this paper we present the study of the solar thermal hybrid power plant, which uses SPT technology, gas turbine, a simple Brayton cycle and operates in the environmental conditions of Ninh Thuan Province (Vietnam), with 2 power levels of $4.6 \mathrm{MW}$ and 11.86 MW. The first power plant of $4.6 \mathrm{MW}$ is equipped with a Mercury TM-50 turbine. The plant includes a heliostat field consisting of 69 units, each with a reflective area of $121 \mathrm{~m}^{2}$. At the second power station with a capacity of 11.86 MW, a PGT-10 turbine is used, and its heliostat area consists of 180 units, each with a reflective area of $121 \mathrm{~m}^{2}$.

\subsection{Climate conditions in Ninh Thuan province of Vietnam}

Ninh Thuan is a coastal province in the South Central Coast of Vietnam. The annual average temperature is $27.7^{\circ} \mathrm{C}$, humidity is $72 \%$, and DNI is $173 \mathrm{~W} / \mathrm{m}^{2}$. This is the most suitable place in Vietnam to build a hybrid solar thermal power plant.

\section{The thermodynamic power plant model}

The scheme of a solar power station with a simple Brighton cycle is shown in Figure 1. Air with ambient temperature after compression in the compressor reaches temperature T2. A portion of air passes through the solar tower and is heated to temperature $\mathrm{T} 3$ in the air heater, and then mixed with the remaining air. Air mixture of temperature $\mathrm{T} 4$ is fed into the combustion chamber, where the fuel is burned. The mixture of combustion products of temperature $\mathrm{T} 5$ is sent to a gas turbine to generate electricity. Exhaust gases are released directly to the environment.

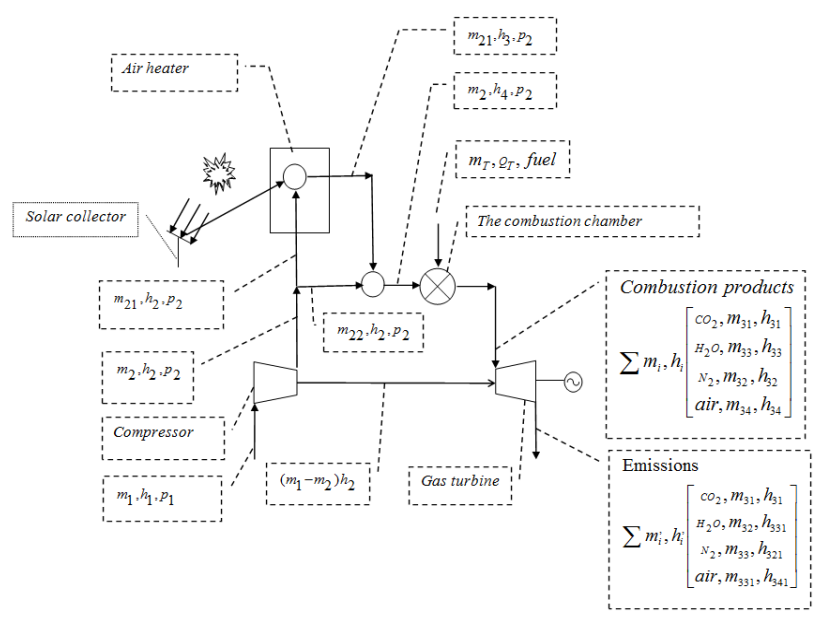

Fig. 1. The schematic diagram of a hybrid mini thermal power plant with solar air heater.

\subsection{Solar collector efficiency}

The solar subsystem receives heat input from the sun given by $D_{a} \cdot S$ where $D_{a}$ is the direct solar irradiance and $S$ is the aperture area of the solar field. The solar irradiance is a function of time because it depends on the sun position during the day, weather conditions, and seasonal fluctuations.

The efficiency of the solar subsystem is determined by the following dependencies:

$$
\begin{gathered}
E_{2}=\varepsilon_{H C} \cdot \dot{E} \\
E_{H S}=\left(T_{3}-T_{2}\right) /\left(T_{H S}-T_{2}\right) \\
\dot{E}=\eta_{0} \cdot D_{a} \cdot S-\alpha \cdot \delta \cdot D_{r} \cdot\left(T_{H S}^{4}-T_{1}^{4}\right)- \\
-U_{L} \cdot D_{r} \cdot\left(T_{H S}-T_{1}\right) \\
\eta_{S}=\frac{\dot{E}}{S \cdot D_{a}}=\eta_{0} \cdot\left[1-X_{1} \cdot\left(T_{H S}^{4}-T_{1}^{4}\right)-X_{2} \cdot\left(T_{H S}-T_{1}\right)\right]
\end{gathered}
$$

After discounting losses, the receiver releases useful energy $E$ to a heat exchanger, which in turn releases a final heat rate $E_{2}$ to the working fluid, $T_{H S}$ is the working temperature of the solar collector, $T_{1}$ is the ambient temperature. $D_{a}$ and $D_{r}$ are, respectively, the aperture and absorber areas; $X_{1}=\frac{\alpha \cdot \delta}{S \cdot C \cdot \eta_{0}} \quad$ and $X_{2}=\frac{U_{L}}{S \cdot C \cdot \eta_{0}}$ are the loss parameters, where $U_{L}$ is the convective heat loss coefficient, $\alpha$ is the effective emissivity of the collector, $C=\frac{D_{a}}{D_{r}} \quad$ is the 
concentration ratio, $\delta=5.67 \cdot 10^{-8} \mathrm{~W} \cdot \mathrm{m}^{-2} \cdot \mathrm{K}^{-4}$ is the Stefan-Boltzmann constant, $\eta_{0}$ is the solar collector efficiency, $\eta_{S}$ is the solar subsystem efficiency.

\subsection{The Brayton gas-turbine efficiency}

The calculation was carried out according to the dependencies presented below:

$$
m_{1} h_{1}+E_{1}=m_{2} h_{2}
$$

Where $m_{1}, m_{2}$ are the mass flows of air at the entrance and at the outlet of the compressor, $\mathrm{kg} / \mathrm{s}\left(m_{1}=m_{2}\right) ; h_{1}, h_{2}$ are the enthalpies of air at the entrance and at the outlet of the compressor, $\mathrm{kJ} / \mathrm{kg} ; E_{1}$ is the energy received from the compressor.

$$
m_{21} h_{2}+E_{2}=m_{21} h_{3}
$$

where $m_{21}$ is the mass flow of air at the entrance and at the outlet of the solar air heater, $\mathrm{kg} / \mathrm{s} ; h_{2}$ is the enthalpy of air entering the solar air heater, $\mathrm{kJ} / \mathrm{kg} ; h_{3}$ is the enthalpy of air leaving the solar air heater, $\mathrm{kJ} / \mathrm{kg} ; E_{2}$ is the energy of solar radiation spent for heating of $m_{2 l}$ air, $\mathrm{kJ}$;

$$
m_{2} h_{4}=m_{21} h_{3}+m_{22} h_{2}
$$

where $m_{22}$ is the mass flow of the remaining air leaving the compressor, $\mathrm{kg} / \mathrm{s} ; h_{4}$ is the enthalpy of the air mixture, $\mathrm{kJ} / \mathrm{kg} ; m_{2}$ is the mass flow of the air mixture, $\mathrm{kg} / \mathrm{s}$;

$$
\begin{aligned}
& m_{2} h_{4}+m_{F} Q_{F}=m_{31} h_{31}+m_{32} h_{32}+ \\
& +m_{33} h_{33}+m_{34} h_{34}=\sum m_{i} h_{i}
\end{aligned}
$$

where $m_{F}$ is the mass fuel consumption, $\mathrm{kg} / \mathrm{s} ; m_{31}, m_{32}$, $m_{33}, m_{34}$ are masses of $\mathrm{CO}_{2}, \mathrm{~N}_{2}, \mathrm{H}_{2} \mathrm{O}$ and air, respectively; $h_{31}$ is the enthalpy of $\mathrm{CO}_{2}$ leaving the combustion chamber, $\mathrm{kJ} / \mathrm{kg} ; h_{32}$ is the enthalpy of $\mathrm{N}_{2}$, leaving the combustion chamber, $\mathrm{kJ} / \mathrm{kg} ; h_{33}$ is the enthalpy of $\mathrm{H}_{2} \mathrm{O}$ leaving the combustion chamber, $\mathrm{kJ} / \mathrm{kg}$; $h_{34}$ is the enthalpy of excess air leaving the combustion chamber, $\mathrm{kJ} / \mathrm{kg} ; Q_{F}$ is the net calorific value of fuel, $\mathrm{kJ} / \mathrm{kg}$.

$$
\begin{aligned}
& m_{31} h_{31}+m_{32} h_{32}+m_{33} h_{33}+m_{34} h_{34}+\left(m_{1}-m_{2}\right) h_{2}= \\
& =E_{3}+m_{31} h_{311}+m_{32} h_{321}+m_{33} h_{331}+m_{341} h_{341}
\end{aligned}
$$

where $m_{341}$ is the mass air flow after the turbine, $\mathrm{kg} / \mathrm{s}$; $h_{311}$ is the enthalpy of $\mathrm{CO}_{2}$ at the turbine outlet, $\mathrm{kJ} / \mathrm{kg}$; $h_{321}$ is the enthalpy of $N_{2}$ at the turbine outlet, $\mathrm{kJ} / \mathrm{kg} ; h_{33 l}$ is the $\mathrm{H}_{2} \mathrm{O}$ enthalpy at the turbine outlet, $\mathrm{kJ} / \mathrm{kg} ; h_{341}$ is the enthalpy of air at the turbine outlet, $\mathrm{kJ} / \mathrm{kg} ; E_{3}$ is the energy produced by the system.

Isentropic compressor efficiency is:

$$
\varepsilon_{C}=\frac{T_{2 S}-T_{1}}{T_{2}-T_{1}}
$$

where $T_{2 S}$ is the temperature of the working fluid after the compression process if it was adiabatic and $T_{2}$ is the actual temperature at the compressor outlet.

Thermal cycle efficiency is:

$$
\begin{gathered}
\varepsilon_{H C}=\frac{T_{5}-T_{4}}{T_{H C}-T_{4}} \\
E_{H C}=\varepsilon_{H C} \cdot \eta_{C} \cdot m_{F} \cdot Q_{F}= \\
=m_{2} \cdot c_{2} \cdot \varepsilon_{H C} \cdot\left(T_{H C}-T_{4}\right)
\end{gathered}
$$

where $T_{H C}$ is the working temperature of the combustion chamber, $E_{H C}$ is the heat input from the combustion chamber, $\eta_{C}$ is the combustion chamber efficiency, $c_{2}$ is the specific heat of air.

The thermal efficiency of the whole system $\eta$ is the ratio between the net mechanical power output $P$ and the total heat input rate:

$$
\eta=\frac{E_{3}}{m_{F} \cdot Q_{F}}
$$

The total heat input rate is:

Table 1. Assessment of efficiency of hybrid mini thermal power plants.

\begin{tabular}{|l|l|l|l|l|l|l|l|l|l|l|l|l|l|l|}
\hline & Jan & Feb & Mar & Apr & May & Jun & Jul & Aug & Sep & Oct & Nov & Dec \\
\hline & \multicolumn{9}{|c|}{ P $4.6 \mathrm{MW}$} \\
\hline$\eta$ & 0.374 & 0.39 & 0.389 & 0.391 & 0.378 & 0.369 & 0.367 & 0.363 & 0.375 & 0.363 & 0.368 & 0.375 \\
\hline$f$ & 0.075 & 0.114 & 0.11 & 0.115 & 0.085 & 0.06 & 0.057 & 0.044 & 0.076 & 0.047 & 0.059 & 0.075 \\
\hline $\begin{array}{l}m_{F} \\
\mathrm{~kg} / \mathrm{s}\end{array}$ & 0.236 & 0.227 & 0.227 & 0.226 & 0.234 & 0.24 & 0.241 & 0.244 & 0.236 & 0.243 & 0.24 & 0.236 \\
\hline & & & & & & & & & & & \\
\hline$\eta$ & 0.342 & 0.356 & 0.354 & 0.356 & 0.345 & 0.337 & 0.336 & 0.332 & 0.342 & 0.333 & 0.337 & 0.342 \\
\hline$f$ & 0.071 & 0.108 & 0.105 & 0.109 & 0.081 & 0.058 & 0.055 & 0.043 & 0.073 & 0.045 & 0.057 & 0.072 \\
\hline $\begin{array}{l}m_{F}, \\
\mathrm{~kg} / \mathrm{s}\end{array}$ & 0.667 & 0.641 & 0.643 & 0.64 & 0.66 & 0.676 & 0.679 & 0.687 & 0.666 & 0.685 & 0.677 & 0.667 \\
\hline
\end{tabular}




$$
E_{H}=E_{2}+E_{H C}
$$

Solar share:

$$
f=\frac{E_{2}}{E_{H}}
$$

\section{Results}

When performing calculations for two hybrid stations with capacities of 4.6 and $11.86 \mathrm{MW}$, the expressions (1-15) were used to obtain results presented in Table 1. The basic version of the calculation assumed the absence of solar radiation $\left(D_{a}=0\right)$. The intensity of solar radiation over time varied in accordance with the climatic conditions of the Ninh Thuan province of the Republic of Vietnam.

\section{Conclusions}

According to the calculations performed for the basic case with no solar radiation, the efficiency of the 4.6 MW power station was $\eta=0.345$, the fuel consumption $\mathrm{mF}=0.056 \mathrm{~kg} / \mathrm{s}$, and for the $11.86 \mathrm{MW}$ station $\eta=0.317$ and $\mathrm{mF}=0.72 \mathrm{~kg} / \mathrm{s}$. During the year efficiency and fuel consumption are constant, since the ambient temperature is almost unchanged. The highest intensity of solar radiation is achieved in February and April. At that time the efficiency is increased by $13.3 \%$ compared to the basic case, while fuel consumption is reduced by $11.7 \%$ (for a $4.6 \mathrm{MW}$ station). For a more powerful station, efficiency is increased by $12.3 \%$ and fuel is reduced by $11.1 \%$. Thus, due to the use of solar energy, substantial fuel savings are achieved.

The reported study was funded by RFBR according to the research project No. 17-08-00295 "A".

\section{References}

[1]

https://www.eia.gov/todayinenergy/detail.php?id=33772. [2]

https://www.eia.gov/todayinenergy/detail.php?id=32912.

[3]https://www.eia.gov/outlooks/aeo/data/browser/\#/ ?id $=67-$

AEO2019\&region $=30 \&$ cases $=$ ref2019\&start $=2017 \&$ end $=2050 \& \mathrm{f}=$ A\&linechart $=$ ref2019-d111618a.6-67-

AEO2019.3-0 ref2019-d111618a.10-67-AEO2019.30 ref2019-d111618a.11-67-AEO2019.3-0 ref2019d111618a.12-67-AEO2019.3-0 ref2019-d111618a.1467-AEO2019.3-0\&ctype=linechart\&sourcekey $=0$.

[4] Powell K M, Rashid K, Ellingwood K, Tuttle J and Iverson B D 2017 Hybrid concentrated solar thermal power systems: a review Renew Sustain Energy Rev 80 (Dec.) 215-37.

[5] Romero-Alvarez M, Zarza E 200 Concentrating solar thermal power In: Handb energy effect renew energy $1-21$.
[6] Jamel M S, Abd Rahman A and Shamsuddin A H 2013 Advances in the integration of solar thermal energy with conventional and non-conventional power plants Renew Sustain Energy Rev 20(Apr.) 71-81.

[7] Sims REH, Rogner H-H and Gregory K 2003 Carbon emission and mitigation cost comparisons between fossil fuel, nuclear and renewable energy resources for electricity generation Energy Policy 31(13) 1315-26.

[8] Powell K M and Edgar T F 2012 Modeling and control of a solar thermal power plant with thermal energy storage Chem Eng Sci 71(Mar.)138-45.

[9] Powell K M and Edgar T F. 2011 Control of a large scale solar thermal energy storage system. Proceedings of the American control conference 1530-5.

[10] Zhao Y, Hong H and Jin H. 2014 Evaluation criteria for enhanced solar-coal hybrid power plant performance Appl Therm Eng 73(1) 577-87.

[11] Saidur R, BoroumandJazi G, Mekhlif S and Jameel M 2012 Exergy analysis of solar energy applications Renew Sustain Energy Rev Jan. 16(1) 3506.

[12] Koroneos C, Spachos T and Moussiopoulos N 2003 Exergy analysis of renewable energy sources Renew Energy 28 (2) 295-310.

[13] https://www.profolus.com/topics/advantagesand-disadvantages-of-concentrated-solar-power/

[14] Peterseim J H, White S, Tadros A and Hellwig U 2013 Concentrated solar power hybrid plants, which technologies are best suited for hybridization Renew Energy 57 520-32.

[15] Burgaleta J I, Arias S and Ramirez D 2012 Gemasolar: The First Tower Thermosolar Commercial Plant with Molten Salt Storage System SolarPACES International Conference 11-14. 